\title{
Determinants' of Farmers' Perception of Climate Variability and Change and Its Effect on Non-Farm Income Diversification
}

\author{
Alemu Mamire Desta Yohannes \\ Wolkite University College of Business and Economics \\ Wolkite University, P.O.Box 07, Wolkite, Guragie Zone, SNNPR, Ethiopia
}

\begin{abstract}
Climate variability and change is now a global phenomenon with growth, poverty, food security, and stability implications. The farmers' Knowledge and awareness about climatic variability and change are important for income diversification planning. The main objective of this study was to assess the determinants of farmers' perception of climate variability and change and its effect on income diversification. A multi-stage sampling procedure used to select the sample respondents and the total sample size of the study was 253 households. Descriptive statistics, logit, and probit regression model were used as data analysis techniques. The descriptive statistics analysis results indicated that about $58.10 \%$ of farmers believe that temperature in the district had become warmer and also over $70 \%$ of respondents were recognized that rainfall volume, pattern, and distribution has changed and $56 \%$ of respondents believed heat intensity is increasing. The logit analyses proved that training participation of the household head, gender, age of household head, level of formal education, local institutional fairness, distance to the nearest market, accesses to extension services, local agroecology and existence of legal obstacle from government were found to have significant influence on the probability of farmers to perceive climate variability change. And the probit analyses identified that perception of farmers on climate variability and change was found to have a positive significant influence on the probability of diversifying their income. It is recommended that local institutions should work with accountably and responsibly and the government should review and improve his rules and regulations which are not comfortable for farmers' livelihood activity.
\end{abstract}

Keywords: Climate Change and Variability, farmers' perception non-farm income diversification

DOI: $10.7176 / \mathrm{JESD} / 12-11-04$

Publication date:June $30^{\text {th }} 2021$

\subsection{Background of study}

Climate variability and change have gained global attention due to its adverse impact on agriculture. Peoples all over the world who depend on nature for their well-being are exposed to climate variability or change and its effects (Desaleg and Walter, 2017). Climate variability and change is now a global phenomenon with growth, poverty, food security, and stability implications. Because of significant dependence on the agricultural sector for production, employment, and export revenues (Mohammed, eta al, 2014). Africa is the most vulnerable continent to climate change due to our dependence on rain-fed agriculture, poor infrastructure, high levels of poverty, and high levels of unemployment. Africa is the hardest hit to climate change despite its little contribution to greenhouse emission due to its dependence on rain-fed agriculture (Selaselet al, 2017) Ethiopia is one of the developing countries in the world and more than 85 percent of the population depends on agriculture for their livelihood. The agricultural sector is especially vulnerable to the adversities of weather and climate since it is rain-fed, done using relatively basic technologies, and on tiny plots of land. People who are already poor and marginalized are struggling to cope with the added burden of increasingly unpredictable weather. It is getting harder and harder for families and communities to bounce back from ever-changing, inconsistent weather affecting their livelihoods, and many have been forced to sell livestock or remove children from school - coping mechanisms that only increase the cycle of vulnerability (OXFAM, 2010)

Determinants of farmer's perceptions are partly based on past observations with a key interest in the recent climatic events to form their perceptions of climatic conditions and to make their decisions about adaptive behavior. However, it is possible that farmers' opinions are influenced by others through communal interactions. This, notwithstanding, the farmers decide on the choice of trends in the climate variables. The adverse effects of climate change on peasant farming have compelled African farmers to develop adaptive strategies to mitigate these effects. Reducing vulnerability means incorporating traditional indigenous knowledge into sustainable (Tesfaye, 2017). Human experience with climate and weather events is often mediated by infrastructure designed to help communities and landowners overcome local climate constraints (e.g. irrigation), withstand extreme events (e.g. floodwalls and levees), and maximize benefits from climate and ecosystem services (e.g. dams for water storage). The extent to which infrastructure is present within a community thus very likely influences how people perceive climate and weather events (Meredith et al., 2017). (Meredith T. Niles Nathaniel D. Mueller and, 2016)

Ethiopia is seriously threatened by climate change, which contributes to frequent drought, flooding, and rising average temperatures. Climate change influences the incidence of poverty as it is directly linked to the agricultural sector, which serves as the source of income and employment for the majority of the poor. Apart from the income 
dimension of poverty, its effect on poverty further extends through its impact on health, education, and access to water (Emerta.A., 2013)The problem of climate change in Ethiopia has the potential of undermining sustainable development efforts if steps are not taken to respond to its adverse consequences (James et al, 2013). This study interested to create awareness on climate variability and change and its effect on non-farm income diversification especially for the farmer those are majority class of our counters' population; the study should first identify determinants of farmers' perception of climate variability and change and its effect on non-farm income diversification. Even though many studies conducted on determinants of farmers' perception of climate variability and change none of them identify the existence of legal obstacles either determinants of farmers' perception of climate variability and change or not well documented.

\subsection{Statement of the Problem}

Nnimmo Bassey, Chair of Friends of the Earth International, said "delaying real action until 2020 is a crime of global proportions. An increase in global temperatures of 4 degrees Celsius, permitted under this plan, is a death sentence for Africa, the Small Island States, and the poor and vulnerable worldwide. This summit has amplified climate apartheid, whereby the richest $1 \%$ of the world has decided that it is acceptable to sacrifice the $99 \%$ ".Mean annual rainfall shows large spatial and temporal variation. Data analyzed in selected stations indicated that temperature has been increasing by $0.370 \mathrm{C}$ every ten years (UNFCCC, 2010). Ethiopia "a country of farmers" has always suffered from great climatic variability and change, including droughts that have contributed to hunger and even famine in the past, the report details how climate change is set to make the lives of the poorest even harder. People who are already poor and marginalized are struggling to cope with the added burden of increasingly unpredictable weather (OXFAM International, 2010). The Ethiopian government wants the country to achieve middle-income status by 2025 in a carbon-neutral way. Climate change poses a huge challenge to Ethiopia's government and people. The country is faced with increasingly unpredictable rains, and sometimes the complete failure of seasonal rains - problems which are linked to climate change. Millions of Ethiopians often face severe food shortages as a result (Kaur, 2013).

Malnutrition among children aged fewer than five (5) is another widespread problem in Ethiopia, and one which could become more prevalent if climate change leads indirectly to food shortages. More severe droughts reduce food production because crops fail and livestock die. Malnutrition, malaria and diarrheal diseases are particularly related to the increased frequency and intensity of floods and droughts in Ethiopia. Climate change projection models indicated that the mean annual temperature in Ethiopia expected to increase from $0.9-1.1^{\circ} \mathrm{C}$ by $2030,1.7-2.1^{\circ} \mathrm{C}$ by 2050 and $2.7-3.4^{\circ} \mathrm{C}$ by 2080 . The ruminant livestock population in Ethiopia shows an increasing trend. However, climate change has a negative impact on population dynamics. In southern Ethiopia, droughts in the 1980 s and 1990 s caused $49 \%$ herd losses under the farmers' condition and $57 \%$ of the cattle mortality under ranch management. As a whole except for goats, other ruminant population dynamics were negatively affected by both temperature

and rainfall distribution (Kefyalew, 2012). In the study area (Silte Zone) there is a climate-related problem such as shortage of water, unseasonal rainfall, increasingly unpredictable rains, and sometimes the complete failure of seasonal rains and sometimes too heavy rainfall which leads to erosion and drought. The recently changing situation of climate has a negative impact on the livelihood of about $95.5 \%$ of the population engaged in agriculture in the study area (SZFED socio-economic abstract, 2017).

Many studies conducted on determinants of farmers' perception of climate variability and change in many developed, developing and underdeveloped countries including Ethiopia. Such studies in those countries including Ethiopia conducted on determinants of farmers' perception of Climate change and variability identified that: sex of household head, age of household head, educational level, farming experience, access to irrigation water, distance to nearest market, access to extension services, local agroecology, family size, farm size, dependency ratio, access to credit, access to weather information, income and access to infrastructures are major determinants of farmers' perception of climate variability and change in many developed, developing and underdeveloped countries including Ethiopia. None of the studies has investigated the effect of farmer's perception of climate variability and change on non-farm income diversification.

\subsection{Objectives of the Study}

To examine the major variables indicating the occurrence of climate variability and change in the study area.

To assess the farmer's perception way of climate variability and change.

To identify determinants of farmer's perception of climate variability and change.

To investigate the effect of farmer's perception of climate variability and change on non-farm income diversification. 


\subsection{Empirical Literature Review}

* Review of Determinants of Farmers' Perception of Climate Variability and its Effect on non-farm Income Diversification

(Limantol et al. (2016), studied determinants of perceptions of climate change and adaptation among Turkana pastoralists in northwestern Kenya. They used Systematic and purposive sampling techniques to select 302 households in Turkana County of northwestern Kenya. Descriptive statistics and Heckman probit models were used to analyses the data obtained from the household's interviews. They found that the majority of households perceive a rise in temperatures and rainfall variability over the past three decades. Pastoralists' perception of climate change was significantly $(\mathrm{p}<.05)$ associated with the gender of the household head, livestock ownership, herd size and access to extension services. According to their study, determinants of climate change include gender and education level of the household head, household size, wealth in terms of livestock ownership, distance to markets, access to credit and extension services. However, they have not conducted the effect of farmers' perception of climate variability and change on income diversification. And also they did not identify local institutional fairness and the existence of legal obstacles from the government is either determinant of farmers' perception of climate variability and change.

(Desalegn Y.and Leal Walter, 2017), Conducted a study on Farmers' perceptions of climate variability and its adverse impacts on crop and livestock production in Ethiopia. They found determinants of farmers' perception of climate variability and its adverse impacts on crop and livestock production by using primary data collected from the group and individual interviews, complemented by observations and a survey. Their study result shows that sex, age, income, and educational level are determinant factors of farmers' perceptions of the manifestations and effects of climate variability on crop and livestock production. However, they have not conducted the effect of farmers' perception of climate variability and change on income diversification. And also they did not identify local institutional fairness and the existence of legal obstacles from the government is either determinant of farmers' perception of climate variability and change.

Uddin et al. (2017) studied the determinants of Farmers' Perception of Climate Change in the Coastal Region of Bangladesh. They used a logit model, along with weighted indexes for ranking and descriptive statistics were used to analyze the result of 100 farmers surveyed by questionnaire. Their study results show that the majority of the farmers $(88 \%)$ perceived changes in climatic conditions. And almost all farmers indicated increases in temperature, droughts, floods, cyclones, salinity levels and decreasing rainfall over the last 20 years. According to their study result, determinants of farms' perception of climate variability include: education, family income, farming experiences and training received are positively significant and Family size and farm size are negatively significant. However, they have not conducted the effect of farmers' perception of climate variability and change on non-farm income diversification. And also they did not identify local institutional fairness and the existence of legal obstacles from the government is either determinant of farmers' perception of climate variability and change.

(Arragaw A. and Woldeamlak B., 2017) conducted a study on determinants of smallholder farmers' choice of coping and adaptation strategies to climate change and variability in the central highlands of Ethiopia by using Binary logistic regression modeling based on a survey of 200 farmers. His study also identified key determinants of farmers' choice of coping and adaptation strategies. The study result shows that for the choice of coping options, agro-ecological zone, and access to markets, farmer-to-farmer extension, landholding size, access to information on climate change, rainfall amount, and educational level of household heads were the significant determinants. The agroecological zone had a negative influence to use selling livestock as a coping strategy while the other variables had positive influences on farmers' choice of coping and adaptation strategies. Off-farm income, community participation, ownership of livestock and temperature, on the other hand, had no significant influence on the choice of coping and adaptation strategies to climate change. However, they have not conducted the effect of farmers' perception of climate variability and change on income diversification. And also they did identify local institutional fairness and the existence of legal obstacles from the government is either determinant of farmers' perception of climate variability and change. perception of climate variability and change.

Brhane et al. (2016) (Gebreyesus B., Tesfahunegn K.and Mekonen Abadi T., 2016)conducted a study on socio-economic, biophysical and institutional characteristics of farmers, and assess the causes, indicators and determinant factors of climate change based on farmers' perception in northern Ethiopia. They had used a Systematic sampling technique to select 60 sample household head farmers. The sample farmers were interviewed using a semi-structured questionnaire. Their study result shows that access to rain-fed agriculture, experience on soil management and water harvesting structures were significantly important determinants of farmers' perception of climate change. But they have not conducted the effect of farmers' perception of climate variability and change on non-farm income diversification. And also they did not identify local institutional fairness and the existence of legal obstacles from the government is either determinant of farmers' perception of climate variability and change.

Meredith et al. (2017) studied Farmer's perceptions of climate change: Associations with observed temperature and precipitation trends, irrigation, and climate beliefs. They obtained data through analysis of historical climate records from local weather stations, interviews $(n=20)$, and a farmer survey $(n=490)$. They 
were examined that those classes of farmers more likely to have irrigation were also significantly more likely to perceive an increase in annual rainfall and that perceptions are influenced by a variety of personal and environmental factors, including infrastructure, which may, in turn, alter decisions about climate adaptation. But they have not conducted the effect of farmers' perception of climate variability and change on non-farm income diversification. And also they did not identify local institutional fairness and the existence of legal obstacles from the government is either determinant of farmers' perception of climate variability and change.

Selase et al. (2017) investigated Climate Variability on Cocoa Farmers Perception and Coping Strategies in the Seaman District of Ghana as the Focal Point. And also they studied the effect of perception of climate variability on adaptation. They used a simple random technique in selecting six (6) communities and respondents (cocoa farmers) from these communities were used since the study area is homogeneously a cocoa growing arena. A total of one hundred and twenty (120) respondents were interviewed with twenty (20) cocoa farmers randomly selected from each community for the study. Their study result shows that factors that positive significantly influenced farmer's perception were FBO membership, household size, residence, educational level of household members and farm management training and specialization of the adaptation strategies to mitigate the adverse impacts of climate variability.

However, they have not conducted the effect of farmers' perception of climate variability and change on nonfarm income diversification. And also they did not identify local institutional fairness and the existence of legal obstacles from the government is either determinant of farmers' perception of climate variability and change. Juana., et al (2013 ) examine Farmers' Perceptions and Adaptations to Climate Change in Sub-Sahara Africa: A Synthesis of Empirical Studies and Implications for Public Policy in African Agriculture. According to their study Years of farming experience, household size, years of education, access to credit facilities, access to extension services and off-farm income are among the significant determinants of Farmers' Perceptions to climate change adaptation measures. And respond to these changes, farmers have adopted crop diversification, planting different crop varieties, changing planting and harvesting dates to correspond to the changing pattern of precipitation, irrigation, planting tree crops, water, and soil conservation techniques, and switching to non-farm income activities. However, they have not conducted the effect of farmers' perception of climate variability and change on non-farm income diversification. And also they did not identify local institutional fairness and the existence of legal obstacles from the government is either determinant of farmers' perception of climate variability and change.

Berhane et al. (2016) analyzed smallholders' perceptions of climate variability in two districts in northern Ethiopia, and the diversification options pursued within and outside agriculture. Their study result shows that diversification outside agriculture is mainly wage labor: international and national migration, construction work in local towns, participation in public works and piecework on nearby farms. And meteorological records corroborate smallholders' belief that temperatures are increasing but do not support assertions that rainfall is decreasing. However, they have not conducted the effect of farmers' perception of climate variability and change on non-farm income diversification. And also they did not identify local institutional fairness and the existence of legal obstacles from the government is either determinant of farmers' perception of climate variability and change.

P. G. Chengappa, C.M. Devika and C.S. Rudragouda( 2017), used probit model to analyze Climate variability and mitigation: perceptions and strategies adopted by traditional coffee growers in India their study result indicated that coffee growers' age, size of landholding, decrease in yield, delay in monsoon, increase in temperature and unpredictability of seasons exert a positive influence on climate-risk ranking, whereas acreage under coffee and crop diversification inversely influenced the ranking of climate risk. However, they have not conducted the effect of farmers' perception of climate variability and change on non-farm income diversification. And also they did not identify local institutional fairness and the existence of legal obstacles from the government is either determinant of farmers' perception of climate variability and change.

Dang et al. (2014) (Hoa Le Dang, Elton Li, Johan Bruwer and Ian Nuberg, 2014) conducted a study on Farmers' perceptions of climate variability and barriers to adaptation: Lessons learned from an exploratory study in Vietnam. They were collecting information from three focus group discussions with 30 male farmers; and six in-depth interviews with one female and five male agricultural officers in the Mekong Delta, Vietnam. Recorded 34-year meteorological data in the delta from 1978 to 2011 is also incorporated to demonstrate the actual climate variability of the region. According to their study result, Casual observation via public media and personal experience dominated farmers' sources of information. Barriers to farmers' adaptation are not exclusively restricted to socio-economic factors and resource constraints; e.g. land tenure, technical knowledge, market, social relationship, credit, information, health care, and demographics. However, they have not conducted the effect of farmers' perception of climate variability and change on non-farm income diversification. And also they did identify local institutional fairness and the existence of legal obstacles from the government is either determinant of farmers' perception of climate variability and change.

Solomon et al. (2015) (FAO, 2015) conduct a study on livelihood diversification and vulnerability to poverty in rural Malawi. They identified that climate variability, associated with farm-income variability, is recognized as one of the main drivers of livelihood diversification strategies in developing countries. Analyzing determinants of 
livelihood diversification choices, to better understand household strategic behavior in the event of climatic risks and other shocks, is important for the formulation of development policies in developing countries highly dependent on rain-fed agriculture, like Malawi. They used geo-referenced farm-household-level data collected in 2010-11 to investigate how climatic variability influences the pattern of diversification that farmers adopt, and the impacts of these choices on welfare. To do so they applied the vulnerability to the expected poverty approach which measures the future level of poverty taking into consideration the role of risk and uncertainty. The analysis considers the effect of policies and institutions such as fertilizer subsidies, extension services, safety-net and credit on diversification choices. According to their study, the results show that higher levels of climate risk generally increase the likelihood of diversification across labor, cropland, and income, suggesting the importance of diversification as a response to constraints imposed by increased risk. In contrast, they found that in areas with favorable average rainfall conditions households are more likely to diversify income, suggesting diversification as a response to opportunities. In terms of welfare, the analysis performed on the components of vulnerability to poverty provides evidence that climatic variables are key determinants of both components of vulnerability (expected consumption and its variance). Fertilizer subsidies are found to be significant in diversification choices for all dimensions and also particularly effective in reducing vulnerability to poverty in high variability environments although the same does not hold for an extension. Looking at differences across gender, they found that women labor diversification is less responsive than men's, resulting in a lower positive impact on expected consumption per capita.

However, they did not examine farmers' perception of climate variability and change is either determines income diversification or not. Schwarze S. and Zeller M. (2004) conducted a study on Income diversification of rural households in Central Sulawesi, Indonesia. They used a Tobit model to evaluate the determinants of nonfarm income diversification shows that the socio-economic status and the access to formal financial markets both have a positive impact. As a measure of the overall diversity of income, we apply the Shannon equitability index, which increases with the number of income sources and their evenness. The access to social capital and the occurrence of crop failures both have a positive impact on the Shannon equitability index, whereas the socio-economic status and the distance to roads have a negative influence. However, they did not examine farmers' perception of climate variability and change is either determines income diversification or not.

Dose (2007) He studied on Securing Household Income among Small-scale Farmers in Kakamega District: Possibilities and Limitations of Diversification. He found that diversification is seen as a way to secure incomes and to increase food security. On the basis of a data set on income security, this paper analyses to what extent this applies to small-scale farmers in Kakamega District, Kenya. Using the sustainable rural livelihoods approach, this paper draws the conclusion, that diversification in agricultural production is not sufficient for securing rural livelihoods in Kakamega District; a sufficient income diversification depends heavily on requirements like access to education, infrastructure, as well as investment capital; and small-scale farmers in Kakamega District in most cases lack these requirements, therefore not being able to achieve secure household incomes or increased food security. However, they did not examine farmers' perception of climate variability and change is either determines income diversification or not.

de Janvry., et al (2005)conducted a study on the Role of Non-Farm Incomes in Reducing Rural Poverty and Inequality in China. They simulate that counterfactual of what rural households' incomes, poverty, and inequality would be in the absence of access to non-farm sources of income. Their study results show that, without non-farm employment, rural poverty would be much higher and deeper, and that income inequality would be higher as well. They found that education, proximity to a town, neighborhood effects, and village effects are crucial in helping particular households gain access to these opportunities. We also find that those who stay as pure farmers have non-observable characteristics that make them much more productive in agriculture, implying positive selection on these characteristics. Moreover, participation in non-farm activities has a positive spillover effect on household farm production. However, they did not examine farmers' perception of climate variability and change is either determines income diversification or not.

(Oyinbo and Olaleye (2016) they studied on Farm Households Livelihood Diversification and Poverty Alleviation in Giwa Local Government Area of Kaduna State, Nigeria. The study utilized primary data collected through a questionnaire administered to 100 respondents selected using purposive and random sampling procedures. Data were analyzed using simple descriptive statistics, the FGT poverty model and the Tobit regression model. However, they did not examine farmers' perception of climate variability and change is either determines income diversification or not.

(Jann Lay and Dana Schüler, 2007)conducted a study on Income Diversification and Poverty in a Growing Agricultural Economy: The Case of Ghana. Our analysis shows that, contrary to common beliefs, rural Ghana has seen the major economic transformation, as households increasingly diversify their livelihoods by both increased migration and more local non-farm employment. These diversification decisions seem to be driven to a large extent by desperation rather than new opportunities, in particular with regard to migration. Low-income households increase their income share in particular from local non-farm activities through more participation while returns 
to diversifying activities stagnate or even decrease. Therefore households with low non-labor asset-base are increasingly diversified and poor. In contrast, asset-rich households are more successful at either diversifying or specializing in those activities the household is relatively good. However, they did not examine farmers' perception of climate variability and change is either determines income diversification or not.

(Asfaw, Solomon \& McCarthy; Nancy \& Paolantonio; Adriana \& Cavatassi; Romina \& Amare; Mulubrhan \& Lipper, Leslie., 2015) studied on Determinants of income diversification among rural households: The case of smallholder farmers in Fedis district, Eastern hararghe zone, Ethiopia. They used the Multinomial logit model was used to pinpoint factors influencing households' participation in non/off-farm activities while the determinants of non/off-farm income were analyzed by Tobit model. Their study results show that participation in non-farm employment activities and the level of income derived are found to be influenced by human capital related variables (gender and age of household head, number of economically active family members, education level of household head and presence of children attending school), livelihood assets (livestock holding, size of cultivated land), livelihood diversifying strategy (crop-based diversification through number of crops grown and harvested) and infrastructure-related variable (proximity to market). The results imply that these factors need to be considered by policymakers in the planning of agricultural and nonagricultural initiatives in this study area. However, they did not examine farmers' perception of climate variability and change is either determines income diversification or not.

(Ashebir D. and Negussie Z., 2015) they conducted a study on nonfarm income diversification and inequality in Eastern Ethiopia: Evidence from Gini Decomposition Analysis. Their study result showed that while non-farm income was inequality-decreasing, farm income was inequality-increasing in the study area. It is also learned that, despite the fact non-farm income and livestock earnings are distributed more unequally than the other sources of income (as reflected in its higher Gini coefficient), its contribution to overall income inequality is the smallest (17\% and $8 \%$ respectively). This is probably because non-farm income comprises the smallest share in total rural income among the respondents, and the Gini correlation of non-farm income with total income rankings is lower than that for the other income sources. However, they did not examine farmers' perception of climate variability and change is either determines non-farm income diversification or not.

Generally, from the above related reviewed literature the study understands that climate variability affects all social, political and economic aspects. As Ethiopia is a "country of farmers" climate variability mainly affects farmers' livelihood. To take a policy action on climate variability, we should first identify the determinants of farmers' perception of climate variability and its adverse effect on income diversification. The related reviewed literature identified determinants of farmers' perception of climate variability include sex of household head, age of household head, educational level, farming experience, access to irrigation water, distance to the nearest market, access to extension services, local agroecology, family size, and farm size. Little studies show that farmers' perception of climate variability has a positive impact on income diversification. However, no study identifies that the existence of legal obstacles and local institutional fairness is either determinants of farmers' perception of climate variability or not.

\section{* Conceptual Framework}

This study examined farmers' perception of variability and change and its effect on non-farm income diversification that was adopted by Silte Zone rural farmers in the Southern Region of Ethiopia. The conceptual framework that guides the study was adapted from the works of Weldlul (2016) (Weldlul, 2016)and it helped as a strategic tool to better understand the interaction between environmental systems, farmers' climate variability and change and non-farm income diversification (Figure 2.1). The conceptual framework takes into consideration the climatic variability and change theory that links climatic variations to environmental changes. Atmospheric changes in greenhouse gas concentration and other drivers change the global climate and this again alters the agricultural output. It contains also determinants of variability and change which play a vital role in this study. Perceived farmers responded by diversifying their non-farm income sources. 


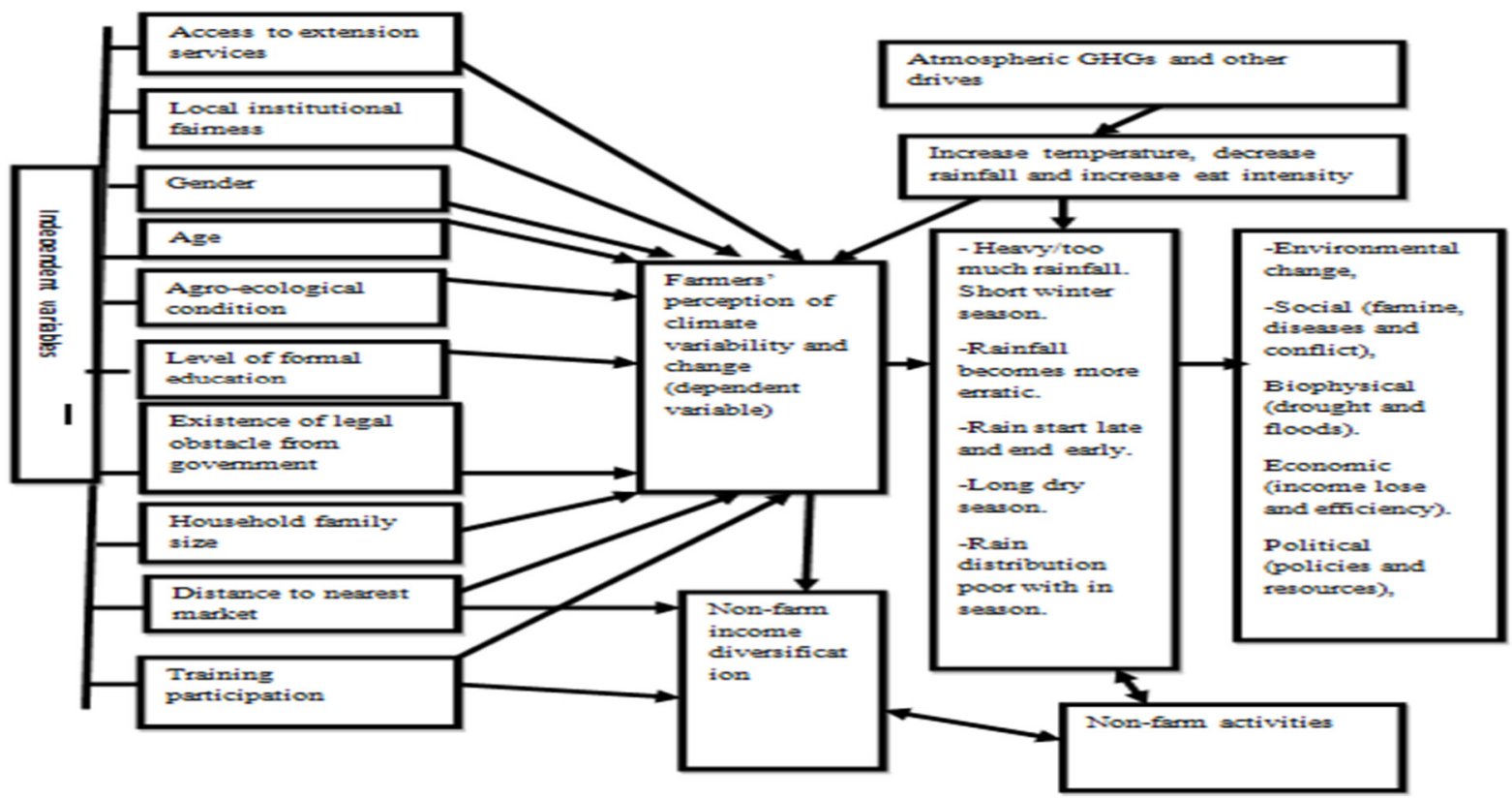

\subsection{Research Methodology}

Types and Data Source

Both primary and secondary data were collected from different sources of data to analyze the study. This study used mainly primary data. The primary data was collected from the selected household by face to face interviews from farmers focused on socio-economic factors determine farmers' perception of climate variability and change, demographic character and situation of climate variability and change indicators. The secondary data was collected from secondary data sources such as the Silte zone finance and economy office which is the source of a household number of 2018 for study area zone woredas and kebele to select analysis to appropriate sample size.

\section{Sampling Techniques and Sample Size}

Because the study interest is on farmers' perception of climate variability and change and its effect on income diversification; the study was conducted in rural areas of Silte Zone. Silte Zone is divided into 8 woredas and 1 city administration and it has 8 towns and 183 PAs in 2017. The sample study areas were selected by Multi-stage Area Sampling technique because the study used both cluster sampling and systematic random sampling methods. The selection of the study areas took into account three distinct Agro-ecological Zones (AEZs).

First, all the woredas were taken for the sake of representativeness and then 4 woredas were selected from the total woredas in the zone based on Agro-ecological Zones by clustering sample method based on geographic location to avoid homogeneity of agro-ecology. Secondly Study Kebeles were identified and arranged into three based on their agroecology, accordingly, two rural kebeles from each woreda selected. And totally of 8 kebeles were selected to represent Highland (Dega), Midland (Woyna-Dega), and Lowland (Kolla) agro-ecological zones respectively. The study was select the total sample size from total population (total number of household in rural areas of Silte Zone) by using formula $n=\frac{z^{2} \times p \times q \times N}{e^{2}(N-1)+z^{2} \times p \times q}$ (Kothari, 2004). then by the proportional method, the study selected a sample from each selected kebele as shown below table 3.1.Sampling distribution.

The following formulas by (Kothari, 2004) (Kothari, 2004) was used to determine sample size: -

$$
\mathrm{n}=\frac{\mathrm{z}^{2} \times \mathrm{p} \times \mathrm{q} \times \mathrm{N}}{\mathrm{e}^{2}(\mathrm{~N}-1)+\mathrm{z}^{2} \times \mathrm{p} \times \mathrm{q}} \quad \mathrm{n}=\frac{(1.96)^{2} \times 0.6 \times(1-0.6) \times 23554}{0.06^{2}(23554-1)+1.96^{2} \times 0.6 \times(1-0.6)}=253
$$

Where: $\mathrm{n}=$ the desired Sample Size, $\mathrm{Z}=$ standard normal deviation (1.96 as per table of area under normal curve for the given confidence level of $95 \%), \mathrm{e}=$ margin of error for this study $6 \%$ was taken $(0.06)$, the generally accepted margin of error for representative sample is $10 \%$ or less. $\mathrm{N}=$ total household number of rural areas of Silte Zone $(23,554)$, taken from Silte Zone finance and economic development office. $p=$ sample proportion, success for each household to be included in the sample, for this study assumed to be 0.6 . $q=1-p=0.4$, failure for each household to be included in the sample. 


\begin{tabular}{|c|c|c|c|c|c|}
\hline Woreda & Total rural household size & percent & Selected kebeles & Household size & Sample size \\
\hline \multirow[t]{2}{*}{ Lauro } & \multirow[t]{2}{*}{6457} & \multirow{2}{*}{$5100=34 \%$} & Girari-woregisa & 559 & 17 \\
\hline & & & Tore_Gixora & 1572 & 47 \\
\hline \multirow[t]{2}{*}{ Hulbereg } & \multirow[t]{2}{*}{3296} & \multirow{2}{*}{$\times 100=17 \%$} & Worebet-shama & 1217 & 37 \\
\hline & & & Bilawanja & 1211 & 36 \\
\hline \multirow[t]{2}{*}{ Halicho } & \multirow[t]{2}{*}{5286} & \multirow{2}{*}{$\times 100=28 \%$} & Abzena-andi & 708 & 21 \\
\hline & & & Edo-andi & 1108 & 33 \\
\hline \multirow[t]{2}{*}{ Misrak -Azernet } & \multirow[t]{2}{*}{4016} & $4016 \times 100=21 \%$ & Adere-abicho & 1274 & 38 \\
\hline & & $\overline{19055}$ & Mehal-adezer & 792 & 24 \\
\hline Total & 19055 & 100 & Total & 8441 & 253 \\
\hline
\end{tabular}

Table: sample distribution

The study was used binary choice format with follow up questions to estimate farmers' perception of climate variability and change and its effect on non-farm income diversification. The questioner was organized into three parts. The first section of the questionnaire used to collect information from the household's demographic characteristics. This includes households' head sex, educational level, family size and age of household head. The second part is farmers' knowledge about climate variability and change and the third part is about the socioeconomic characteristics of farm households.

The study was used a face to face interview survey method to collect the data from the selected households. The advantage of face to face interview survey method from other survey methods it is more likely to gain reliable estimates of conservational value with its strength in achieving higher response rates, to avoid the interviewer bias. As most of the population in rural areas have low education level, face to face interviews is the most effective method of survey.

\section{Method of Data Analysis and Presentation}

The study was used in both descriptive and inferential techniques to analyze the data. The method of data presentation included tables and charts. In the first part of the analysis, the study was used descriptive statistics such as percentages, means, and standard deviations. In the second part, econometric models specification such as binary logit and probit model was employed. The study used a logit model to analyze the determinants of farmers' perception of climate variability and change. And the study used a second probit model to analyze the effect of farmers' perception of non-farm income diversification. Variables that play important roles in determinants of farmers' perception of climate variability and change and its effect on non-farm income diversification in rural areas of the Silte zone were analyzed through these models. In this part, STATA software was used to estimate the coefficients of the variables in these models.

\section{Econometric Model Specification of Logit Regression}

As discussed in the above the study used both binary logistic and probit regression models to estimate farmers' perception of climate variability and change and its effect on non-farm income diversification in Silte Zone. The study was used two models because of a binary logistic regression model to identify factors influencing farmers 'perception of climate variability and change, and probit regression to know the effect of farmers' perception of climate variability and change on non-farm income diversification. In a binary logistic regression model, the dependent variable is dichotomous in nature taking a value of 1 or 0. Although the Ordinary Least Squares (OLS) method may compute estimates for the binary choice models, certain assumptions of the classical regression model were violated. These include non-normality of disturbances, heteroscedastic variances of the disturbances, and questionable value of $R^{2}$ as a measure of goodness of fit (Gujarati., 2004)

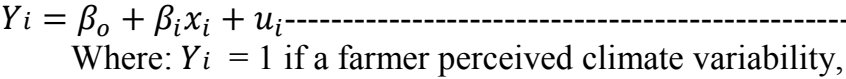

$$
\begin{aligned}
& Y_{i}=0 \text { if a farmer does not }
\end{aligned}
$$

$\beta$ is intercept, $\beta$ is a parameter to be estimated, $x_{i}$ is variable in question, and $u_{i}$ is a disturbance term. This model is a typical linear regression model, but because the regression is binary or dichotomous, it is called a linear probability model (LPM). However, in a regression model, when the dependent variable is binary in nature, taking value 1 or 0 ; the use of linear probability models becomes a major problem. This is because the predicted value can fall outside the relevant range of zero to one probability value. Thus, if linear probability models are used, results may fail to meet statistical assumptions necessary to validate conclusions based on the hypothesis tested. Gujarati (2003) recommended Logit and probit models to overcome the problem associated with LPM. These models use Maximum Likelihood Estimation (MLE) procedures and ensure that probabilities are bound between 0 and 1 . Both logit and probit transformations estimate the cumulative distribution, thereby eliminating the interval 0, 1 problem associated with LPM.

The logistic cumulative probability function can be represented by

$$
p_{i}=f\left(z_{i}\right)=\frac{1}{1+e^{-z_{i}}}------------(2)
$$


Where $p_{i}$ the probability is that $\mathrm{i}^{\text {th }}$ personally will be in I-first category, $z_{i}=\beta_{o}+\beta_{i} x_{i}+u_{i}$ where $\beta_{o}$ is intercept of the model; $\beta$ is model parameters to be estimated; $x_{i}$ are the independent variables and e represents the base of natural logarithms, which is approximately equal to 2.718 . In equation (2), $\mathrm{Z}$ can range from positive infinity to negative infinity. The probability of a farmer perceiving climate change lies between 0 and 1 . If we multiply both sides of the equation (2)

$$
\begin{aligned}
& \text { By } 1+e^{-z_{i}} \quad \text { we get: } \\
& \left(1+e^{-z_{i}}\right) p_{i}=1------------------(3)
\end{aligned}
$$

Dividing by $\mathrm{P}$ and then subtracting 1 we get:

$$
e^{-z_{1}}=\frac{1}{p_{i}}=\frac{1-p_{i}}{p_{i}}------------------(4)
$$

By definition; however, $e^{-z_{i}}=1 / e^{z_{i}}$ so that the equation (4) becomes

$$
e^{-z_{i}}=\frac{1-p_{i}}{p_{i}}-----------------(5)
$$

By taking the natural logarithm of both sides of equation (5), we get:

$z_{i}=\log \left(\frac{1-p_{i}}{p_{i}}\right)--------(6)$ In other words: $z_{i}=\log \left(\frac{1-p_{i}}{p_{i}}\right)=\beta_{o}+\beta_{i} x_{i}--------(7)$

This makes the logistic probability model.

Therefore, it can be noted that the logistic model defined in equation (7) is based on the logits of Z, which constitutes the stimulus index. Marginal effects can also be computed to show changes in probability when there is a unit change in independent variables. Marginal effects are computed as:

$$
\begin{gathered}
\frac{\partial p k}{\partial x k}=\frac{\beta k e^{-z k}}{\left(1+e^{-z k}\right)^{z}}------------------(8) \\
z_{i}=\beta_{i} x_{i}+u_{i}-----------------(9)
\end{gathered}
$$

The specified logit model for this study is thus:

$$
\begin{aligned}
& Z^{i}=\beta^{1}+\beta^{2} X^{2 i}+\cdots+\beta^{k} X^{k i} \\
& z_{i}=\beta x_{i}+u_{i}
\end{aligned}
$$

Where: $z_{i}$ is the perception by the ith farmer that climate is changing, $x_{i}$ is the vector of explanatory variables of the probability of perceiving climate change by the ith farmer, $\beta$ is the vector of the parameter estimates of the regressors hypothesized to influence the probability of farmer is a perception about climate change.

As one of the objectives of this study was the assessment of determinants of farmers "perception of climate variability and change and its effect on income diversification practiced by smallholder farmers. Some of these factors are considered as explanatory variables in the model. This study used a binary Logit model to analyze the determinants of farmers' perception of climate variability and change because it is widely used in perception studies involving binary choices. Accordingly, household demographic characteristics, socioeconomic characteristics and institutional factors were hypothesized to explain the dependent variable and the study considered the following Variables as potential factors affecting farmers' perception of climate variability and change.

Perception $($ PCVC) $=$ F (Gender of household (GENDER), Age of the respondent (AGE), Formal Educational level of the respondent (FEL), Training participation of household(TP), Distance to nearest market(DNM),Agroecological condition (AEC),Access to extension services(AES),Local institutional fairness(LIF), Existence of legal obstacle from government(ELOG))

The binary Logit model expressed using the codes of variables are as follows:

$\left.\mathrm{PCVC}=f\left(\beta_{i}{ }^{\prime} x i\right)\right)=\mathrm{F}(\mathrm{GENDER}+\mathrm{Age}+\mathrm{FEL}+\mathrm{TP}+\mathrm{DNM}+\mathrm{AEC}+\mathrm{AES}+\mathrm{LIF}+\mathrm{ELOG}+)+\mu_{\mathrm{i}}$

Where: $\mathrm{PCVC}$ is a dummy variable indicating farmer perception of climate variability and change that is related to it as $\mathrm{PCVC}=1$ if farmer perceived, Otherwise $\mathrm{PCVC}=0$

$x_{i}$ are the variables determining the perception of climate variability and change in the Logit model,

$\beta^{i}$ is an unknown parameter to be estimated in the Logit regression model, ui is a random error term

\section{Probit Model}

The study was used this model to identify the effect of farmer's perception of climate variability and change on non-farm income diversification. The probit model makes use of the normal distribution:

$$
\rho r(\gamma=1 / \chi)=\int_{-\infty}^{x} \phi(t) d t=\phi\left(\chi^{\prime} \beta\right)
$$

Where $\phi(t)$ is the standard normal density: $\phi(\mathrm{t})=\frac{e^{\left(-\frac{t}{2}\right)}}{\sqrt{2 \pi}}$ and $\phi($.$) is the standard normal distribution function.$

The corresponding marginal effect is given by: $\frac{\partial \epsilon(y / x)}{\partial x}=\left\{\frac{\phi\left(x^{\prime} \beta\right)}{\partial x}\right\} \beta=\phi\left(x^{\prime} \beta\right) \beta$ Where $\phi\left(x^{\prime} \beta\right)$ is the scale factor. 


\section{Econometric Model Specification of Probit Regression}

As one of the objectives of this study was to investigate the effect of farmer's perception of climate variability and change on non-farm income diversification practiced by smallholder farmers. Some of the factors are considered as explanatory variables in the model. This study used a probit model to analyze the effect of farmers' perception of climate variability and change on income diversification because it is widely used in effect studies involving binary choices. Accordingly, household demographic characteristics, socioeconomic characteristics and institutional factors were hypothesized to explain the dependent variable and the study considered the following Variables as potential factors affecting farmers' perception of climate variability and change.

The specified probit model for this study is thus:

Number of non-farm income sources (NIS) =F (Perception of climate variability and change (PCVC), distance to nearest market (DNM), training participation(TP), household family size(HFS), level of formal education(LFE), gender, access to extension services(AES), farmland size(FL), access to irrigation water (AIRW)) The probit model expressed using the codes of variables are as follows:

$N I S=f\left(\beta_{i}{ }^{\prime} x i\right)=F(P C V C+D N M+T P+H F S+L F E+G E N D E R+A E S+F L+A I R W)+\mu_{i}$

Where: NIS is a dummy variable indicating the number of non-farm income sources that is related to it as NIS $=$ 1 if NIS $>1$ and NIS $=0$ if NIS $=1$

$x_{i}$ are the variables determining the number of non-farm income sources in the Probit model,

$\beta^{i}$ is an unknown parameter to be estimated in the probit regression model, ui is a random error term variables in the models

\begin{tabular}{|c|l|l|l|}
\hline $\mathrm{S} / \mathrm{N}$ & Explanatory variable & Expected sign & Remark \\
\hline 1. & perception of climate change and variable & Dependant variable & \\
\hline 2. & Sex of household head (dummy) & Independent variable & Male 1 Female 0 \\
\hline 3. & Age of household head & Independent variable & \\
\hline 4. & Existence of legal obstacles(dummy) & Independent variable & Existed 1, not Existed 0 \\
\hline 5. & farming experience & Independent variable & \\
\hline 6. & Education level & Independent variable & \\
\hline 7. & access to irrigation water & Independent variable & Have access 1, have no access 2 \\
\hline 8. & Distance to the nearest market & Independent variable & \\
\hline 9. & local agro-ecology & Independent variable & Daga 0, Woyna-daga 1, kola 2 \\
\hline 10. & Access to extension services (dummy) & Independent variable & $\begin{array}{l}\text { Have access 1 Have no access } \\
0\end{array}$ \\
\hline 11. & Family Size & Independent variable & \\
\hline 12. & Number of income sources & Independent variable & \\
\hline 13. & Training participation (TP) (dummy) & Independent variable & $\begin{array}{l}\text { Participated 1 Not participated } \\
0\end{array}$ \\
\hline 14. & Local institutional fairness(LIF)(dummy) & Independent variable & Fair 1 unfair 0 \\
\hline 15. & Farm size & Independent variable & \\
\hline
\end{tabular}

Source: Own design (2018) 


\subsection{Findings and Interpretation}

Farmers' Perception of Climate Variability and Change

Result for Farmers' Perception of Climate Variability and Change and Its Marginal Effects after Logit

Table 4.18 Logistic Regression

Logistic regression result

$$
\text { Variable Coef. }
$$

Gender

Age

HFS

TP ${ }^{*}$

LFE

DNM

AEC

AES

FL

LIF $^{*}$

ELOG

constant

$$
1.513211 * *
$$

$.0468929 * *$

.0742827

$1.823268 * * *$

$.3204809 * * *$

$-.5543001 * * *$

$1.176784 * *$

$1.243002 * * *$

$-1.25083^{*}$

$1.25083 * *$

$-1.364495 * *$

$-2.899419$
Std.Err

.638304

.0183112

.1211786

.4823982

.0929377

.1279719

.5492973

.4418244

.4189966

.6000265

.5709203

1331872

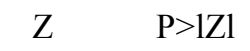

2.37

2.56

0.61

3.78

3.45

$-4.33$

2.14

2.81

$-1.65$

2.08

$-2.39$

$-2.18$
Marginal Effects After Logit

$$
\frac{d x}{d y}
$$$$
.3557946
$$

.0102762

.0162785

.3937075

.0702311

$-.1214708$

.231525

.2751885

$-.1517489$

.2639451

$-.285907$

\begin{tabular}{|l|c|}
\hline Number of observation & 253 \\
\hline LR chi2(11) & 184.41 \\
\hline Prob $>$ chi2 & 0.0000 \\
\hline Pseudo R-Squared & 0.5332 \\
\hline
\end{tabular}

Source: survey data in 2018 .

Table 4.18 below presents the binary logistic regression coefficient together with marginal effects after the dependent variable (perception) was regressed on a set of explanatory variables that have been discussed beforehand. Those factors had a significant influence on farmers 'perception of climate variability and change. In this section, the factors associated with the perception that climate is changing by sample Silte zone respondents are investigated.

Despite the fact that the majority of the farmers interviewed claimed that they perceive as the climate is changing, some of the farmers who perceived climate change did not respond by increasing the number of income sources. It falls out that both farmers who perceive and responded and also those not responded share some common characteristics, which assist in better understanding the reasons underlying their perception. From the model results, a positive estimated coefficient implies an increase in the farmers' perception of climate variability and change with the increased value of the explanatory variable. Whereas the negative estimated coefficient in the model implies decreasing perception with an increase in the value of the explanatory variable. The results from the binary regression model analyses of the sampled households are presented in Table 15 . The model outputs from regression indicated that most of the independent variables have significantly influenced the smallholder farmers 'perception of climate variability and change variability. The results revealed that the gender, age, educational level, agro-ecological condition, training participation, access to extension services, distance to nearest market, existence of legal obstacle from government and local institutional fairness have significant relationship with farmers' perception to climate variability and change have positively and significantly influenced the perception of the farmers about the change in climate conditions over years. Whereas distance to the nearest market and the existence of legal obstacles from the government have a negatively significant influence on farmer's perception of climate variability and change. The results of the correlation between independent variables show that there is no serious multi-collinearity problem.

From the model output (table 4.18), it is clear that gender influences how they perceive climate variables. It is clear that Male headed households seen to perceive better than their counterparts. Male-headed households are often considered to be more likely to get information about new technologies and take risky businesses than female-headed households. The result in table 4.18 below shows that being male-headed households increases the chance of perception of farmers' climate variability and change by $35.57 \%$. Ayal et al. (2017) argued that femaleheaded households have less chance than males on the perception of climate variability and change. Female-headed households are less likely to have the perception of climate variability and change. The male-headed households have a better level of perception of climate change as compared to female-headed households; this is maybe because of the network of a family in accessing information which indicates differential access of gender to climate change information issues. This result is in line with the argument that male-headed households are often considered to be more likely to get information about new technologies, climate and take risky businesses than 
female-headed households. The age of household head has a positive impact on the perception of climate variability and change because higher age has a higher probability to gain knowledge of environmental situations such as climate variability and change. The result in table 4.18 below shows that one-year increases in the age of farmers from the baseline age of 50 increase the chance of perception of climate variability and change by $1.02 \%$.

With respect to education, it can be observed that education also has a role in influencing the way farmers perceive climate change and variability, which is consistent with (Mamba, 2016), findings who also observed that farmers with a higher level of education perceived environmental factor and climate variables correctly and vice versa. This means that any effort to help farmers perceive correctly needs to also focus on improving the level of education of farmers, particularly to equip then with skills relating to farming as it could be observed that farmers who possess skills or has been trained in certain skills perceive climate variables better followed by those with tertiary or at least secondary education. This suggests that to help improve how farmers perceive of climate variables, formal education must be emphasized Farming household heads with higher education are more likely to perceive changes in climate than those with less farming experience and less education.

The point that education has a significant association with perception implies the capability of educated farmers to better access information about climate change compared to those with less education. The result of the logistic model in table 4.18 below shows that education increases in one grade from baseline grade 2 increases the probability of farmers' perception of climate variability and change by $7.023 \%$. Also, other Studies such as Weldlul (2016) and Juana et al. (2013) show that with more education, farmers develop knowledge and skill that may help them sense risks better. Access to extension services (AES) is also crucial in shaping perception. Those farmers with access to extension services tend to perceive correctly the importance of improving farmers' perception of climate variability and change. It is therefore important factors influencing farmers 'perception of climate variability and change. The findings indicate that access to extension services affects how farmers perceive climate variables. Those farmers with access to extension services tend to perceive correctly the climate variability and change. The result in table 4.18 below shows that having access to extension services increases the probability of farmers' perception of climate variability and change by $39.37 \%$. It is similar to (Limantol et al., 2016) studied access to extension services that affect farmers' perception of climate variability and change. Training participation (TP) has a positive impact on farmers' perception of climate variability and change .Farmers those who gain TP have a higher probability to gain knowledge about their environment than those who do not participate in training. The result in table 15 below shows that training participation increases the probability of farmers' perception of climate variability and change increases by $39.37 \%$. Which is conformed to study of Uddin et al. (2017) argued that training participation enhances the probability that farmers' perception is taken.

Regarding distance to the nearest market (DNM), the model output has shown that distance from the market was negatively related to the perception of climate change though not found as such significant. This is due to the fact that the more a farmer is distant from the output market and local institution, the less likely he or she can have more contacts for information sharing. Market places are usually the place where rural households exchange information regarding all matters of the agricultural activities as well as socio-economic issues. Market places in the study location are very few, where some of the farmers were required to travel more than $6 \mathrm{~km}$ to reach the market place. It has a negative impact on farmers' perception of climate variability. Since farmers who live far from the market can get less information about environmental issues than farmers who live near to the market. The study results in table 15 below show that one $\mathrm{km}$ increases from the baseline distance to the nearest market 4.228 decreases the probability of farmers' perception of climate variability and change by $12.15 \%$ at a $1 \%$ significance level. Weldlul (2016) studied that distance to the nearest market decreases the probability that farmers' perception is taken. According to agro-ecological condition (AEC) farmers who live in highland and lowland far from local institutional services and do not there is poor infrastructure compared to farmers who live in midland. The study result in table 15 below shows that being in midland increases the probability of farmers' perception of climate variability and change by $23.15 \%$. Local Institutional fairness (LIF) has a positive impact on farmers' perception of climate variability. Since if there is the fairness of institution farmers take attention to environmental issues and if there is no fairness of institution; the opposite is true. If farmers take attention to their environment they observe and discuss their environmental issues this enhances perception about climate variability and change. The study result in table 15 below shows that the existence of local fairness (LIF) increases the probability of farmers' perception of climate variability and change by $26.39 \%$.

Existence of legal obstacles from the government (ELOG) it is property right that did not give full right. And also it is democratic and human right which does not give full confidence to live anywhere without discrimination. It has a negative on farmers' perception of climate variability and change. Because of legal obstacle farmers' may ignore any community-based discussion from government or/and non-government institutions. In this study, the existence of legal obstacles from the government is negatively influencing farmers' perception of climate variability and change. The study result in table 4.18 below shows that the Existence of legal obstacles from the government (ELOG decreases the probability of farmers' perception of climate variability and change by $28.59 \%$. 
Effect of Farmers' Perception of Climate Variability and Change and Its Marginal Effect after Probit Table 4.19 Probit Regression Results

Probit regression result

\begin{tabular}{|c|c|c|c|c|c|}
\hline Variable & Coef. & Std.Err. & Z & $\mathrm{P}>1 \mathrm{Zl}$ & $\begin{array}{ll} & \text { probit } \\
d x & \end{array}$ \\
\hline $\mathrm{PCVC}^{*}$ & $1.686615^{* * *}$ & .6217872 & 2.71 & 0.007 & .0283735 \\
\hline DNM & $-.5213977 * * *$ & .1262207 & -4.13 & 0.000 & .0026866 \\
\hline TP* & $1.261633 * * *$ & .4485413 & 2.81 & 0.005 & .0127545 \\
\hline HFS & $-.1629364 * *$ & .0806867 & -2.02 & 0.043 & -.0008395 \\
\hline AIRW* & -.6794932 & .4074126 & -1.67 & 0.095 & -.0069828 \\
\hline LFE & -.0325645 & .07048 & -0.46 & 0.644 & -.0001678 \\
\hline GENDER* $*$ & $.7304484^{*}$ & .3359938 & 2.17 & 0.030 & .008192 \\
\hline AES* & $.8055225^{*}$ & .4415132 & 1.82 & 0.068 & .0053858 \\
\hline FL & .1167095 & .3179158 & 0.82 & 0.714 & .0006014 \\
\hline Constant & 3.404844 & .9118961 & 3.73 & 0.000 & \\
\hline \multicolumn{2}{|c|}{ Number of observation } & \multicolumn{4}{|c|}{253} \\
\hline \multicolumn{2}{|l|}{ LR $\operatorname{chi} 2(9)$} & \multicolumn{4}{|c|}{118.01} \\
\hline \multicolumn{2}{|l|}{ Prob $>$ chi 2} & \multicolumn{4}{|c|}{0.0000} \\
\hline \multicolumn{2}{|c|}{ Pseudo R-Squared } & \multicolumn{4}{|c|}{0.5701} \\
\hline
\end{tabular}

Source: survey data in 2018.

From table4.19 above presents the probit regression coefficient together with marginal effects after the dependent variable was regressed on a set of explanatory variables that have been discussed beforehand. Those factors had a significant influence on the Number of non-farm income sources. In this section, the factors associated with the Number of non-farm income sources (NIS) by sample Silte zone respondents are investigated.

From table4.19 perception of climate variability and change (PCVC) is independent in the case of identifying the effect of farmers' perception of climate variability and change on non-farm income diversification. It has a positive impact on income diversification. Farmers who perceived climate variability and change have a probability of diversifying their non-farm income. Income diversification uses as self-insurance against risks and shocks due to climate variability and change; many farmers did not diversify their non-farm income due to lack of awareness about climate variability and change. The study result of the probit model in table 4.19 below shows that farmers' perception of climate variability and change increases the probability of diversifying their non-farm income sources by $2.83 \%$. This implies that farmers' perception of climate variability and change has a positive impact on non-farm income diversification.

Regarding distance to the nearest market, a one-kilometer increase in distance to the nearest market decreases the probability of non-farm income sources by $0.26 \%$. According to training participation, Participating in training increases the probability of non-farm income sources by $1.27 \%$. According to household family size, one member increases in family size decreases the probability of non-farm income sources by $0.083 \%$. Lastly according to gender, being male increases the probability of non-farm income sources by $0.082 \%$.

\section{Conclusion}

The study set out to evaluate farmers 'perceptions of climate variability and change and its effect on income diversification in Silte Zone Southern Ethiopia. It was found out that the majority of the farmers were well aware that climate was changing and it was the cause of the recurrent droughts that were ravaging the district. The majority of the farmers noted that there was an increase in temperature, increases in heat intensity and rainfall volume, distribution and timing has changed. Also, there was a change in the pattern of rains and an increase in the frequency of droughts. According to the findings of the study, farmers' perception and awareness about the changing temperature volume and heat intensity, rainfall amount, distribution, onset and offset, increased frequency and intensity of weather and climatic extreme events is high.

The high level of perception was a result of access to awareness-raising campaigns by the educated household head and access to extension service, access to extension services, farmer's location in terms of agro-ecology, closeness to market, educational level, and training participation. However, the way farmers perceived the changes in a climate significantly varies across agro-ecologies, the existence of legal obstacles from the government, gender, and educational level. Although the majority of farmers appear to be well aware of climate change, few seem to actively undertake income diversification measures to counteract climate change. Indeed. This can imply that though perception is a necessary ingredient for non-farm income diversification strategies.

The results from the study also show that training participation of the household head, gender, age, education, access to extension services, and existence of legal obstacles from government, distance to the nearest market; 
local agroecology and local institutional fairness were crucial factors in influencing the likelihood of farmers to perceive climate variability and change. The output of the binary logistic regression analyses proved that training participation of the household head, gender, age, level of education, local agroecology, local institutional fairness and access to extension services were found to have a positive significant influence on the probability of farmers to perceive climate variability and change. Distance to the nearest market and the existence of legal obstacles from the government was found to have a negatively significant influence on the probability of farmers to perceive climate variability and change. The output of the probit regression analyses indicated that farmers' perception of climate variability and change was found to have a positive significant influence on non-farm income sources diversification. Also, training participation and gender were found to have a positive significant influence on nonfarm income sources diversification. Distances to the nearest market and household family size were found to have a negatively significant influence on non-farm income sources diversification.

\section{Bibliography}

[1]. Alain de Janvry, Elisabeth Sadoulet, and Nong Zhu. (2005). The Role of Non-Farm Incomes in Reducing Rural Poverty and Inequality in China. INRS-UCS, University of Quebec, 1-29.

[2]. Aphu Elvis Selase1, L. X. (2017). Climate Variability: Cocoa Farmers Perception and Coping Strategies, Seaman District of Ghana as the Focal Point. Huazhong University of Science and Technology.

[3]. Arragaw A. and Woldeamlak B. (2017). Determinants of Smallholder Farmers' Choice of Coping and Adaptation Strategies to Climate Change and Variability in the Central Highlands of Ethiopia. Environmental development 24, 22(7), 77-85,DOI: 10.1016/j.envde.2017.06.006.

[4]. Asfaw, Solomon \& McCarthy, Nancy \& Paolantonio, Adriana \& Cavatassi, Romina \& Amare, Mulubrhan \& Lipper, Leslie, (2015). Asfaw, Solomon"Livelihood diversification and vulnerability to poverty in rural Malawi,". ESA Working Papers 288974, Food and Agriculture Organization.

[5]. Ashebir D. and Negussie Z. (2015). Nonfarm income diversification and inequality in Eastern Ethiopia: Evidence from Gini Decomposition Analysis. Dilla University, P.O.BOX 419.

[6]. Desalegn Y.and Leal Walter. (2017). Farmers' Perceptions of Climate Variability and its Adverse Impacts on Crop and Livestock Production in Ethiopia. Journal of Arid Environment, 2028,DOI:10.1016/j.jaridev.2017.01.007.

[7]. Desalegn Yayeh Ayal and Walter Leal Filho. (2017). Farmers' perceptions of climate variability and its adverse impacts on crop and livestock production in Ethiopia. 20-28.

[8]. Dose, H. (2007). Securing Household Income among Small-scale Farmers in Kakamega District: Possibilities and Limitations of Diversification. GIGA working paper 41, GIGA German Insititute of Global and area studies.

[9]. Emerta.A. (2013). Climate change, growth, and Poverty in Ethiopia. Working Paper No.3. Ethiopia.

[10].FAO. (2015). Livelihood diversification and vulnerability to poverty in rural Malawi, by Solomon Asfaw, Nancy McCarthy, Adriana Paolantonio, Romina Cavatassi, Mulubrhan. Rome: Food and Agriculture Organization of the United Nations.

[11]. Gebreyesus B., Tesfahunegn K.and Mekonen Abadi T. (2016). Farmers' Perception of Causes, Indicators, and Determinants of Climate Change in Northern Ethiopia: Implication for developing Adaptation Strategies. Applied Geography, 73, 1-12,DOI: https://doi.org/10.1016/j.apgeog.2016.05.009.

[12]. Gujarati. (2004). Basic econometrics, (4 ed.). The MC craw-Hill companies.

[13].Hoa Le Dang, Elton Li, Johan Bruwer and Ian Nuberg. (2014). Farmers' Perceptions of Climate Variability and Barriers to Adaptation: Lessons Learned from an Exploratory Study in Vietnam. Mitigation and Adaptation Strategies for Global Change, 19, 531-548.

[14].James Sharka Juana.,Zibanani Kahaka and Francis Nathan Okurut. ( 2013 ). Farmers' Perceptions and Adaptations to Climate Change in Sub-Sahara Africa: A Synthesis of Empirical Studies and Implications for Public Policy in African Agriculture. Journal of Agricultural Science, 5( 4).

[15].Kothari, C. R. (2004). Research Methodology; Methods and Techniques (2nd revised edition ed.). New Delhi: New age international limited.

[16].Limantol A., Keith B., Azabre B, and Lennartz B. (2016). Farmers' perception and adaptation practice to climate variability and change: a case study of the Vea catchment in Ghana. Graduate Research Program (GRP) Climate Change and Water Resources, West African Science Service Center on Climate Change and Adapted Land Use (WASCAL), University of Abomey-Calavi, Cotonou, Benin.

[17]. Mamba, S. F. (2016). Factors Influencing Perception of Climate Variability and Change among Smallholder Farmers in Swaziland. Indian Journal of Nutrition, 3(2).

[18]. Meredith T. Niles Nathaniel D. Muellerand. (2016). Farmer Perceptions of Climate Change: Associations with Observed Temperature and Precipitation Trends, Irrigation, and Climate Beliefs. Global Environmental Change, 39, 133-142.

[19]. Mohammed Nasir Uddin, Wolfgang Bokelmann and. (2014). Factors Affecting Farmers' Adaptation 
Strategies to Environmental Degradation and Climate Change Effects: A Farm Level Study in Bangladesh. Jason Scott Entsminger(2), 223-241.

[20]. Schwarze S. and Zeller M. (2004). Income diversification of rural households in Central Sulawesi, Indonesia. Journal of International Agriculture, 44(44), 61-73.

[21].SZFED.(2017) Silte Zone socio-economic abstract.

[22]. Tesfaye Samuel Saguye. 2017. Assessment of Farmers' Perception of Climate Change and Variability and its Implication for Implementation of Climate-Smart Agricultural Practices: the Case of Geze Gofa District, Southern Ethiopia.

[23]. OXFAM, I. (2010). Climate Change Increasing Poverty and Vulnerability in Ethiopia.

[24]. Oyakhilomen Oyinbo and Kehinde Tobi Olaleye. (2016). Farm Households Livelihood Diversification and Poverty Alleviation in GiwaLocalGovernment Area of Kaduna State, Nigeria. The Journal of Sustainable Development, 15(1), 219- 232.

[25].P. G. Chengappa, C.M. Devika and C.S. Rudragouda. (2017). Climate variability and mitigation: perceptions and strategies adopted by traditional coffee growers in India. Climate and Development.

[26]. Weldlul, A. L. (2016). Analysis of Smallholder Farmers' Perceptions of Climate Change and Adaptation Strategies to Climate Change: The Case of Western Amhara Region, Ethiopia. 